\section{Pacific Northwest}

National Laboratory

Operated by Battelle for the

U.S. Department of Energy

\title{
Pressure Sensor Calibration using VIPA Hardware
}

\author{
Rey Suarez \\ Tom Heimbigner \\ Joel Forrester \\ James Hayes \\ Lance Lidey
}

October 2008

Prepared for the U.S. Department of Energy under Contract DE-AC05-76RL01830 


\section{DISCLAIMER}

This report was prepared as an account of work sponsored by an agency of the United States Government. Neither the United States Government nor any agency thereof, nor Battelle Memorial Institute, nor any of their employees, makes any warranty, express or implied, or assumes any legal liability or responsibility for the accuracy, completeness, or usefulness of any information, apparatus, product, or process disclosed, or represents that its use would not infringe privately owned rights. Reference herein to any specific commercial product, process, or service by trade name, trademark, manufacturer, or otherwise does not necessarily constitute or imply its endorsement, recommendation, or favoring by the United States Government or any agency thereof, or Battelle Memorial Institute. The views and opinions of authors expressed herein do not necessarily state or reflect those of the United States Government or any agency thereof.

PACIFIC NORTHWEST NATIONAL LABORATORY operated by

BATTELLE for the

UNITED STATES DEPARTMENT OF ENERGY under Contract DE-AC05-76RL01830

Printed in the United States of America

Available to DOE and DOE contractors from the Office of Scientific and Technical Information, P.O. Box 62, Oak Ridge, TN 37831-0062;

ph: (865) 576-8401

fax: (865) 576-5728

email: reports@adonis.osti.gov

Available to the public from the National Technical Information Service, U.S. Department of Commerce, 5285 Port Royal Rd., Springfield, VA 22161

ph: (800) 553-6847

fax: (703) 605-6900

email: orders@ntis.fedworld.gov

online ordering: http://www.ntis.gov/ordering.htm 


\title{
Pressure Sensor Calibration using VIPA Hardware
}

\author{
Rey Suarez James Hayes \\ Tom Heimbigner Lance Lidey \\ Joel Forrester
}

October 2008

Prepared for the U.S. Department of Energy under Contract DE-AC05-76RL01830

Pacific Northwest National Laboratory

Richland, Washington 99352 


\section{Pressure Sensor Calibration using VIPA Hardware}

\section{Introduction/Background}

The pressure sensors used in the Deployable Analysis System output an analog voltage representative of the current pressure the sensor is reading. This output voltage range may be different for different sensors, but is generally between 0 and 5 volts, or 0 and 10 volts. This means that if you have a pressure sensor that has a pressure range of 0 to $100 \mathrm{psi}$, and output voltage range of 0 to 10 volts, then when the sensor would output 10 volts when it senses 100psi. Similarly, if the pressure is 0 psi, the voltage output of the pressure sensor would read 0 volts.

The VIPA hardware uses a series of modules to control the system. One of the modules that the VIPA hardware uses is a 16-bit analog input module. The main purpose of this module is to read in a voltage. The inputs of these modules are connected directly to the voltage outputs of all the pressure sensors in the system. Because the sensors have different pressure and voltage output ranges, it is necessary to calibrate and scale the sensors so that the values make sense to the operator of the system.

\section{VIPA and Hardware Menu Programs}

VIPA is a hardware control system that provides a way to communicate digital and analog signals to and from a computer that is running VIPA communication software. In the case of DAS, a program called vipaServer is used to communicate to the VIPA hardware. vipaServer reads and writes analog and digital values to the VIPA hardware. VIPA analog signals are all in raw voltage units. A configuration file, vipa.cfg, exists for the vipaServer that maps all the channels to a physical location on the hardware. This makes it possible for a user to ask vipaServer for the voltage on channel 3, for example, and vipaServer would return the current voltage value for that channel. The program users can use to talk to vipaServer is called vipaMenu. vipaMenu is a small menu driven program that allows users to get and set channels on the VIPA hardware. This program is generally used for debugging and testing. vipaMenu may be launched from the DAS source directory with the command: ./vipaMenu .

As stated above vipaServer provides all analog values in raw voltages. There exists, another server program called hardwareServer that provides scaling of the voltage units. This server communicates to vipaServer and has the ability to scale voltages to more useful engineering units such as PSI or Torr. The scaling parameters are set in a configuration file called hardware.cfg that hardwareServer reads when it is first started. This file is located in a directory called "cfg" located within the main das source directory.

The scaling for voltage sensors uses gain and offset. This comes from the standard linear equation $y=m x+b$, where $m$ is the slope (gain) and $b$ is the $y$-intercept (or offset). In 
the case of a pressure sensor the equation becomes Pressure $=\mathrm{m} *$ voltage $+\mathrm{b}$. Figure 2.0 below is a snapshot of the hardware configuration file.

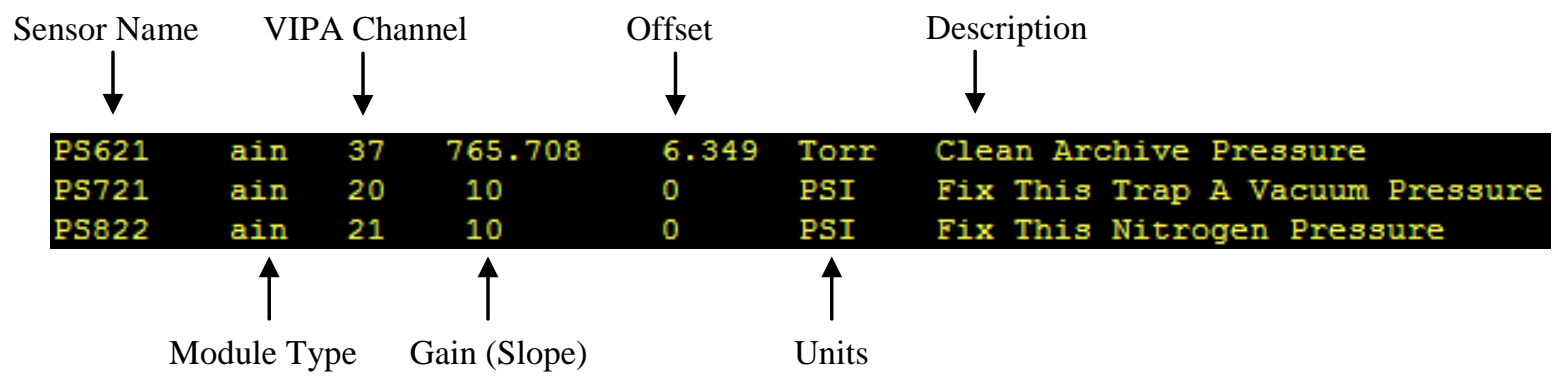

Figure 2.0 Snapshot of hardware configuration file (hardware.cfg).

The two columns that need to be modified in this file for performing calibration are the gain and offset for a particular sensor. The "units" column should also be modified to match the desired unit of measure for a given sensor.

In order to communicate with the hardwareServer, a hardwareMenu application exists. This program can be launched by running: ./hardwareMenu within the DAS source directory. When a pressure sensor value is requested using the hardwareMenu program, a value in engineering units is returned based on the offset and gain settings.

The vipaServer and hardwareServer refer to signals differently. The vipaServer refers to inputs and outputs as channel numbers. The hardwareServer uses sensor names. This information exists in the hardware configuration file (hardware.cfg). Figure 2.0 above, shows a Sensor Name and a corresponding VIPA Channel. In this case, if we wanted to find the voltage for sensor "PS621", we would launch vipaMenu and ask for analog input channel 37. To read this same sensor in engineering units with hardwareMenu, when prompted for the analog sensor name "ps621" would be entered.

The gain and offset are only applied when the hardwareServer is first launched, so if the configuration file is updated with a gain and offset number, it will need to be terminated and restarted. The server can be terminated through the hardwareMenu program.

Figure 2.1 below depicts the process of acquiring a reading form a pressure sensor. This starts from the pressure sensor, where the voltage is generated and illustrates the propagation of that voltage until it is read in software. 


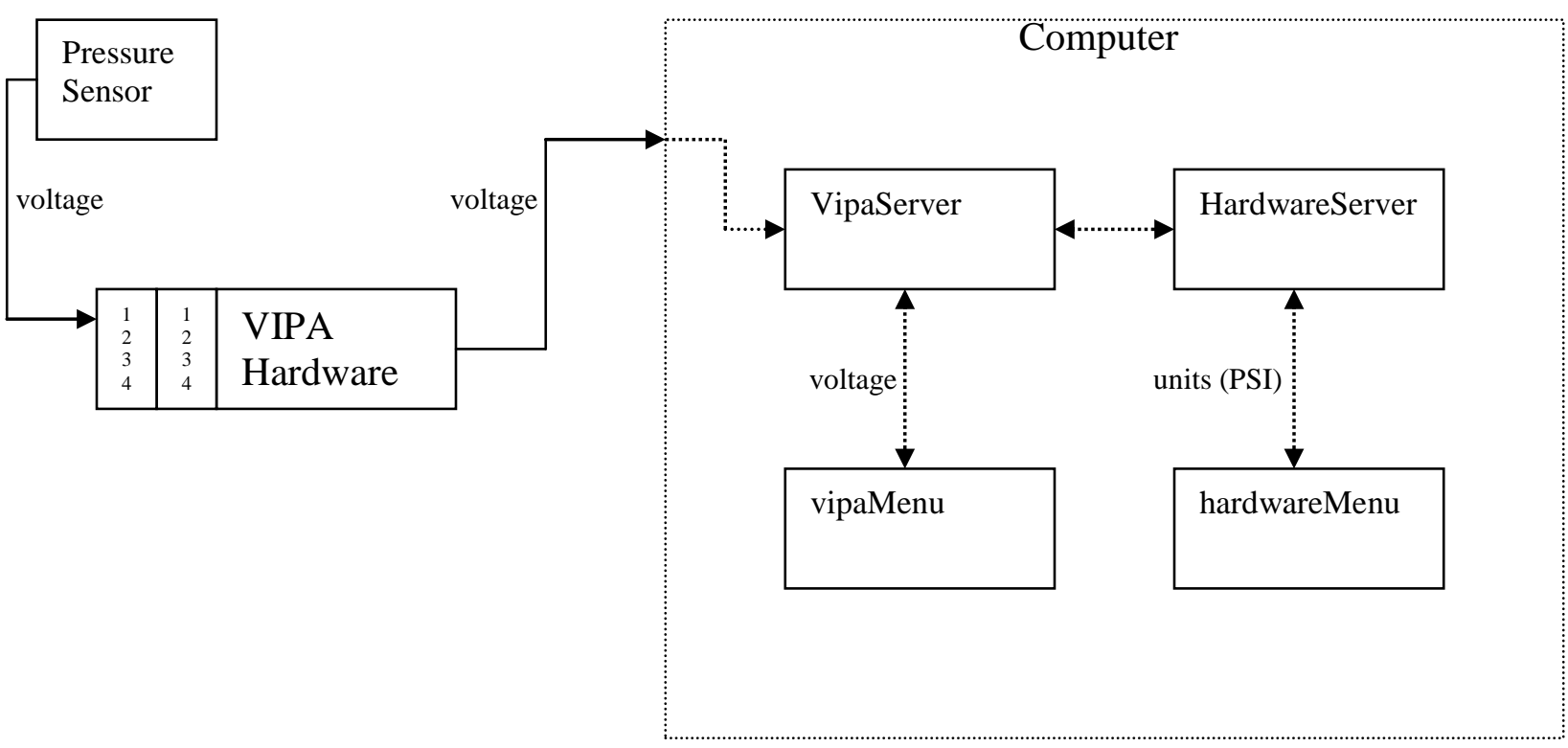

Figure 2.1 Propagation of sensor reading through the system.

This is a subset of the servers that are actually running on the system, but these are the ones necessary for calibrating the system.

In general, the vipaMenu program will be used to read out the raw voltages from the sensor and the hardwareMenu program will be used verify the results. Since the guided user interface (GUI) also communicates with the hardware server, it may also be used to verify the results. As previously stated, use the hardware configuration file to figure out what channel number the vipaServer is using to communicate to a particular sensor.

\section{Calibration}

The method used to calibrate these sensors is to apply a gain and offset. This is possible because the output of the pressure sensors is linear. The idea is to apply the general linear equation: $y=m x+b$, where $m$ is the slope (or gain) and $b$ is the offset. In the case of a pressure sensor, the equation looks as follows:

Pressure $=m^{*}$ vipaVoltage + offset

where vipaVoltage is the voltage read in from the output of the pressure sensor. The terms that need to be calculated and entered into the hardware configuration file are $m$ and offset. This method of calibration requires the user to have a calibrated pressure guage that can be used for measuring pressure at the different ranges. The method for calibrating the sensor is as follows: 


\section{Measure low pressure information}

a. put the sensor under vacuum

b. record calibrated low pressure reading from calibrated pressure guage

(this value will be the calibratedLowPressureReading)

c. using vipaMenu, record the low pressure voltage from the sensor

(this value will be the lowPressureVolage)

\section{Measure high pressure information}

a. put sensor at atmospheric pressure

b. record calibrated high pressure reading from calibrated pressure guage

(this value will be the calibratedHighPressureReading)

c. using vipaMenu, record the high pressure voltage from the sensor

(this will be the highPressureVoltage)

\section{Calculation}

a. Using the information obtained from steps $1 \& 2$, calculate gain and offset for the sensor.

Recall that the equation for calculating pressure is:

Pressure $=m^{*}$ vipaVoltage + offset

To find $\mathrm{m}$, the slope, use the following equation:

$$
m=\frac{\text { calibratedHigh } \operatorname{Pr} \text { essure } \operatorname{Re} \text { ading }- \text { calibratedLow } \operatorname{Pr} \text { essure } \operatorname{Re} \text { ading }}{\text { high } \operatorname{Pr} \text { essureVoltage }- \text { low } \operatorname{Pr} \text { essureVoltage }}
$$

After the slope is determined, the offset may be calculated with either of the equations below:

offset $=$ calibratedLow $\operatorname{Pr}$ essure $\operatorname{Re}$ ading $-(m *$ low Pr essureVoltage $)$

or

offset $=$ calibratedHigh Pressure Re ading $-(m *$ high Pr essureVoltage $)$

The plot below illustrates the basic idea of the calibration for a sensor. Notice that in this case a 5.4 voltage reading from the sensor corresponds to a 64 psi pressure reading. 
PNNL-17719

100 PSI Pressure Sensor

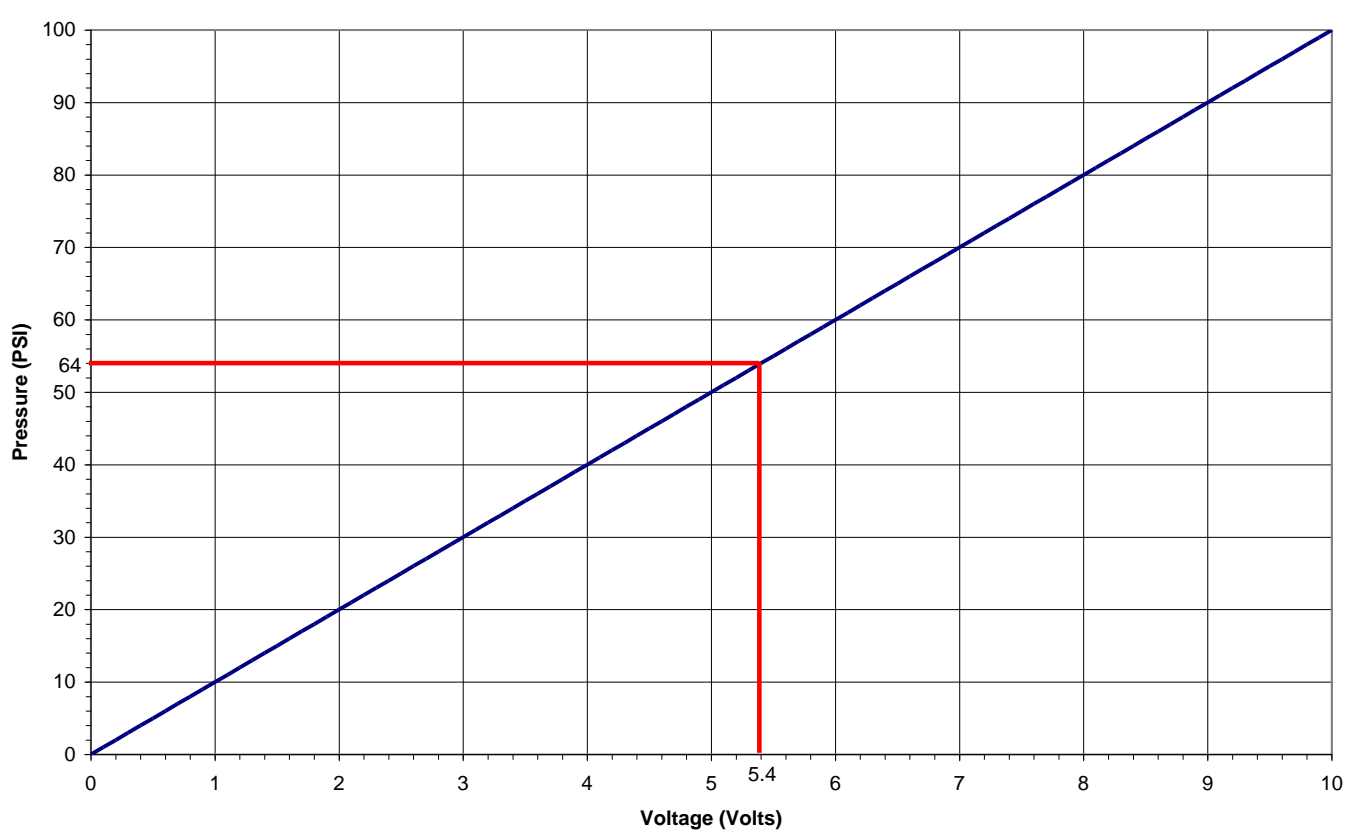

Figure 3.0 Calibration plot for 100 psi sensor with 0 to 10 volt output 